\title{
MARCADORES RAPD PARA MAPEAMENTO GENÉTICO E SELEÇÃO DE HÍBRIDOS DE CITROS ${ }^{1}$
}

\author{
ROBERTO PEDROSO DE OLIVEIRA2; MARIÂNGELA CRISTOFANI ${ }^{3}$; MARCOS ANTÔNIO MACHADO
}

RESUMO - Os marcadores moleculares apresentam várias aplicações no melhoramento de plantas, permitindo uma série de análises genéticas. Este trabalho foi realizado com o objetivo de estabelecer marcadores RAPD para serem utilizados em estudos de mapeamento genético e na seleção de híbridos entre tangerina-'Cravo' (Citrus reticulata Blanco) e laranja-'Pêra' (C. sinensis (L.) Osbeck). Extraiuse DNA de folhas dos parentais e de seis híbridos $F_{1}$. As reações de amplificação foram preparadas em 13 uL de solução, constituída por tampão 1x GIBCO BRL; soluções 1,54 mM de $\mathrm{MgCl}_{2}$ e $0,2 \mathrm{mM}$ de cada dNTP; $15 \mathrm{ng}$ de cada 'primer'; 1,5 unidade de 'Taq DNA Polymerase' e $15 \mathrm{ng}$ de DNA genômico. As reações foram realizadas em termocicladores programados para 36 ciclos de 1 min a $92^{\circ} \mathrm{C}$, 1 min a $36^{\circ} \mathrm{C}, 2$ min a $72^{\circ} \mathrm{C}$ e 10 min de extensão a $72^{\circ} \mathrm{C}$. Foram testados 'primers' decâmeros arbitrários dos 'kits' $\mathrm{A}, \mathrm{AB}, \mathrm{AT}, \mathrm{AV}, \mathrm{B}, \mathrm{C}$, $\mathrm{D}, \mathrm{E}, \mathrm{G}, \mathrm{H}, \mathrm{M}, \mathrm{N}, \mathrm{P}, \mathrm{Q}, \mathrm{R}$ e U da Operon, sendo selecionados 113 por apresentarem polimorfismo, com número de marcadores variando de 1 a 6 por 'primer'. Esses 'primers' amplificaram 201 (23,13\%) bandas polimórficas, aplicáveis no mapeamento genético e seleção de híbridos. A freqüência de 'primers' com 1;2; 3; 4; 5 e 6 bandas polimórficas foi de 49,5\%,33,6\%, 9,7\%,4,4\%, 1,8\% e 1,0\%, respectivamente.

Termos para indexação: laranja-‘Pêra', tangerina- ‘Cravo’, híbridos, marcadores moleculares

\section{RAPD MARKERS TO GENETIC MAPPING AND SELECTION OF CITRUS HYBRIDS}

\begin{abstract}
Molecular markers have many applications in plant breeding, enabling some types of genetic analyses. The aim of this work was to establish RAPD markers to be used to genetic mapping studies and selection of hybrids between 'Cravo' tangerine (Citrus reticulata Blanco) and 'Pêra' orange (C. sinensis $\left(\mathrm{L}\right.$.) Osbeck). DNA of the parents and six hybrids $\mathrm{F}_{1}$ was isolated from the leaves. The amplification reactions were performed in volumes of $13 \mu \mathrm{L}$, composed by GIBCO BRL 1x buffer, $1,54 \mathrm{mM} \mathrm{MgCl}, 0,2 \mathrm{mM}$ of each dNTP, $15 \mathrm{ng}$ of each primer, 1,5 unit of Taq DNA Polymerase and $15 \mathrm{ng}$ of genomic DNA. These reactions were carried out in thermocyclers programmed for 36 cycles of $1 \mathrm{~min}$ at $92^{\circ} \mathrm{C}, 1 \mathrm{~min}$ at $36^{\circ} \mathrm{C}, 2 \mathrm{~min}$ at $72^{\circ} \mathrm{C}$ and $10 \mathrm{~min}$ of extension at $72^{\circ} \mathrm{C}$. It were evaluated random decamer primers of the kits A, AB, AT, AV, B, C, D, E, G, H, M, N, P, Q, R e U from Operon. One hundred thirteen primers were selected as polymorphics, with number of markers varying from 1 to 6 per primer. These primers amplified $201(23,13 \%)$ polymorphic fragments, with application in genetic mapping and selection of hybrids. The frequency of primers with 1, 2, 3, 4, 5 and 6 polymorphic fragments was $49,5 \%, 33,6 \%, 9,7 \%, 4,4 \%, 1,8 \%$ e $1,0 \%$, respectively.
\end{abstract}

Index terms: ‘Pêra' sweet orange, ‘Cravo’ tangerine, hybrids, molecular makers

\section{INTRODUÇÃO}

Fatores de natureza biótica e abiótica afetam de modo significativo a cultura dos citros no Brasil. O melhoramento genético apresenta limitações relacionadas à longa juvenilidade, incompatibilidade, alta heterozigosidade, esterilidade, depressão por endogamia, apomixia e poliploidia (Gmitter et al., 1996).

Plantas híbridas entre tangerina- 'Cravo' (Citrus reticulata Blanco) e laranja-'Pêra' (C. sinensis (L.) Osbeck) são potencialmente importantes por segregarem para diversas características de importância agronômica, principalmente para o caráter resistência/suscetibilidade a doenças, entre as quais a clorose variegada dos citros (CVC). A laranja-'Pêra' é altamente suscetível à doença e a tangerina- 'Cravo' não tem apresentado sintomas no campo (Machado et al., 1993).

Diversos marcadores moleculares têm sido utilizados no melhoramento genético de plantas, permitindo análises mais completas e consistentes de sua genética. No melhoramento de citros, vêm sendo utilizados na seleção precoce de híbridos e plantas nucelares (Oliveira et al., 2000), obtenção de 'fingerprints' de cultivares (Deng et al., 1995), caracterização de germoplasma (Machado et al., 1996), estudos de relações filogenéticas entre espécies e gêneros (Federici et al., 1988), construção de mapas genéticos de alta cobertura genômica e na localização de genes de interesse econômico (Cai et al., 1994; Gmitter et al., 1996; Simone et al., 1998; Cristofani et al., 1999).

Atualmente, os RAPDs (Random Amplified Polymorphic DNA) consistem em um dos marcadores moleculares mais usados em estudos genéticos. Os RAPDs são detectados pela amplificação, de forma arbitrária, de fragmentos de DNA de diferentes tamanhos pela reação de polimerase em cadeia (PCR), na presença da enzima termoestável 'DNA polimerase' (Williams et al., 1990).

As principais vantagens do RAPD referem-se à fácil

1 (Trabalho 261/2000). Recebido: 27/11/2000. Aceito para publicação: 21/09/2001. Extraído da tese de Doutorado, a ser apresentada pelo primeiro autor ao CENA-USP, Piracicaba-SP.

2 Eng. Agr., M.Sc., Embrapa-Centro de Pesquisa Agropecuária de Clima Temperado (CPACT), Caixa Postal 403, CEP 96001-970, Pelotas-RS. Email: rpedroso@cena.usp.br

3 Eng. Agr., Ph.D., Centro de Citricultura 'Sylvio Moreira' (CCSM-IAC), Caixa Postal 04, CEP 13490-970, Cordeirópolis-SP. Email: fiac@siteplanet.com.br 
execução, rápida obtenção de marcadores, necessidade de pequenas quantidades de DNA genômico (10 a $100 \mathrm{ng})$, baixo custo, ausência de hibridação, não-utilização de radioisótopos, polimorfismo ser visualizado na forma de banda amplificada de DNA visível em gel de agarose corado com brometo de etídio, polimorfismo ser detectado em regiões altamente repetitivas e um nível elevado de polimorfismo quando se compara com outros marcadores moleculares. As desvantagens relacionam-se à reprodutibilidade dos resultados, ambigüidade na interpretação das bandas, co-migração de fragmentos de igual ou tamanho muito próximo e ao caráter dominante da maioria dos marcadores obtidos (Cruz \& Milach, 1998; Ferreira \& Grattapaglia, 1998).

Este trabalho teve por objetivo estabelecer marcadores RAPDs consistentes que possam ser utilizados em estudos de mapeamento genético e seleção de híbridos entre tangerina'Cravo' e laranja- 'Pêra'.

\section{MATERIAL E MÉTODOS}

Folhas frescas e maduras dos parentais tangerina- 'Cravo' e laranja-'Pêra', e de seis híbridos $F_{1}$ desses genitores, obtidos por cruzamentos controlados, foram utilizadas para a extração de DNA. As folhas foram lavadas em água corrente, secas com papel toalha e trituradas em almofariz com nitrogênio líquido. A extração de DNA foi feita utilizando o protocolo de Murray \& Thompson (1980), adaptado por Cristofani et al. (1999), que utilizam o método CTAB.

A quantificação do DNA foi feita em gel de agarose, corado com brometo de etídio $\left(0,5 \mathrm{ng} \mathrm{mL}^{-1}\right)$, comparando-se a $\lambda$ DNA intato nas concentrações de 50; 100; 150 e $200 \mathrm{ng} \mathrm{iL}^{-1}$ (Sambrook et al., 1989). De acordo com os mesmos autores, a qualidade do DNA extraído foi avaliada com base na ausência/ presença e intensidade de rastro no gel após corrida eletroforética.

As reações de amplificação foram preparadas em um volume final de $13 \mathrm{uL}$, com 1,3 uL de tampão 10x (200 mM Tris$\mathrm{HCl} \mathrm{pH} \mathrm{8,4;} 500 \mathrm{mM} \mathrm{KCl}$ - GIBCO BRL); soluções 1,54 mM de $\mathrm{MgCl}_{2}$ (GIBCO BRL) e 0,2 mM de cada dNTP (dATP, dCTP, dTTP, dGTP - GIBCO BRL); 15 ng de cada 'primer'; 1,5 unidade de 'Taq DNA Polymerase' (GIBCO BRL); e 15 ng de DNA genômico. Adicionou-se $20 \mathrm{uL}$ de óleo mineral (Sigma) por reação. As amplificações foram realizadas em termocicladores MJ Research Inc., programados para 36 ciclos de $1 \mathrm{~min}$ a $92^{\circ} \mathrm{C}, 1 \mathrm{~min}$ a $36^{\circ} \mathrm{C}, 2$ min a $72^{\circ} \mathrm{C}$ e 10 min de extensão a $72^{\circ} \mathrm{C}$. Foram avaliados 'primers' decâmeros de seqüência arbitrária dos 'kits' A, AB, AT, AV, B, C, D, E, G, H, M, N, P, Q, R e U da Operon Technologies Inc., Alameda, CA, USA.

Os produtos de amplificação foram separados por eletroforese em tampão TAE $1 \mathrm{X}(0,04 \mathrm{M}$ Tris-acetato $+1 \mathrm{mM}$ EDTA), utilizando géis de agarose a $1,4 \%$, contendo $5 \mathrm{ug} \mathrm{mL} \mathrm{m}^{-1} \mathrm{de}$ brometo de etídio. A corrida foi realizada a $94 \mathrm{~V}$, sendo aplicados 5 uL da solução de reação com 1 uL de tampão de carregamento $(0,25 \%$ de azul de bromofenol $+40 \%$ de sacarose $)$ por canaleta do gel. O marcador 'DNA Ladder' de $1 \mathrm{~kb}$ (GIBCO BRL) foi utilizado como padrão. A visualização das bandas foi realizada sob luz ultravioleta.

Os 'primers' testados foram avaliados quanto ao número total de bandas geradas, número de marcadores encontrados e intensidade das bandas polimórficas. As bandas polimórficas foram classificadas em 'fortes' para amplificações de grande intensidade e nitidez, e 'moderadas' para amplificações de intensidade média. As amplificações polimórficas visíveis de pouca intensidade e nitidez não foram consideradas.

Os produtos polimórficos de amplificação foram designados de acordo com o 'primer' e tamanho da banda amplificada.

\section{RESULTADOS E DISCUSSÃO}

O protocolo utilizado para a extração de DNA das amostras de citros apresentou uma eficiência média de $4 \mu \mathrm{g}$ de DNA/200 $\mathrm{mg}$ de folha fresca, com valores variando de $2,5 \mathrm{a} 10 \mu \mathrm{g}$. O DNA extraído foi de boa qualidade, pois, praticamente, não houve rastro nos géis de quantificação, indicando baixo nível de degradação.

As reações de amplificação apresentaram elevada reprodutibilidade, não havendo diferenças entre os termocicladores. Segundo Cruz \& Milach (1998) e Ferreira \& Grattapaglia (1998), a reprodutibilidade está fortemente associada à qualidade do DNA e à padronização das condições de reação. Keil \& Griffin (1994) também obtiveram padrões de bandas RAPDs bastante consistentes, ao trabalharem com Eucalyptus, verificando pequena ou nenhuma variação durante as repetições. Foram amplificadas, em média, 7,8 bandas por 'primer', com valores variando de 1 a 16. Machado et al. (1996) e Coletta Filho et al. (1998) obtiveram, respectivamente, médias de 5,3 e 4,7 bandas
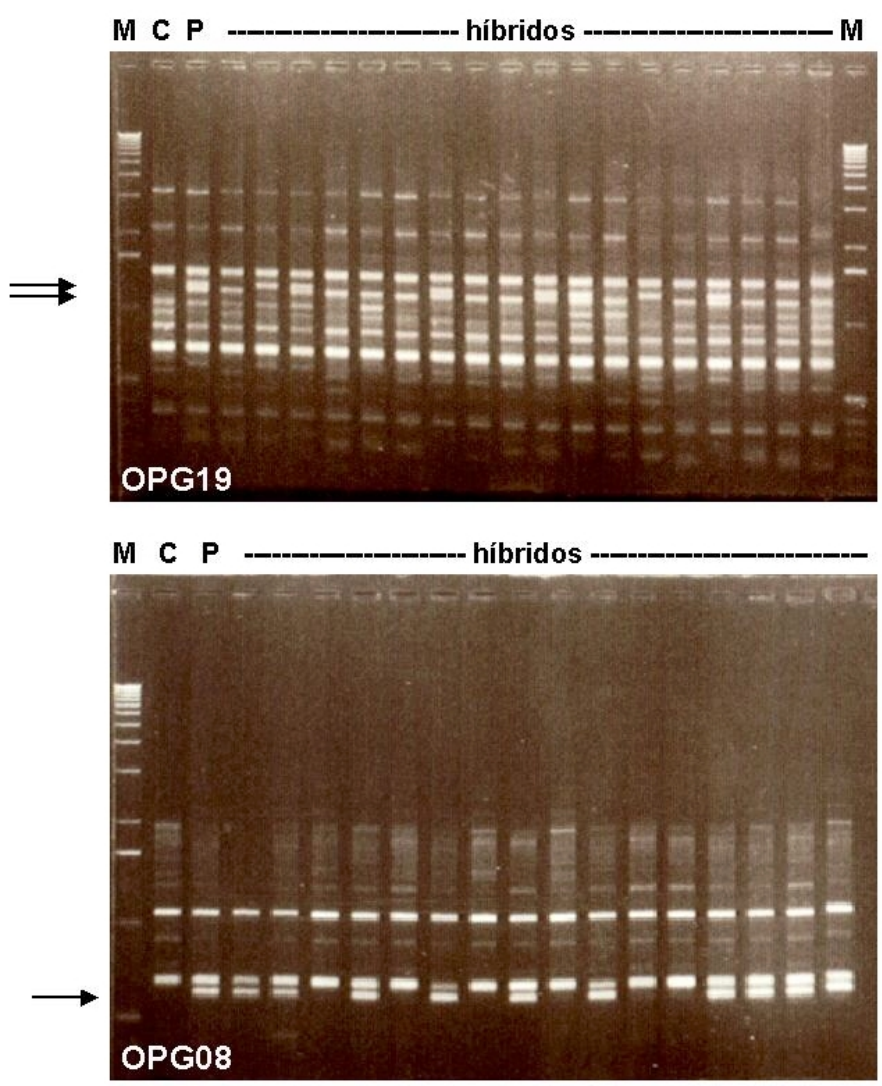

FIGURA 1- Reações de amplificação com os 'primers' OPG19 e OPG08, sendo M: marcador de $1 \mathrm{~kb}$; C: tangerina'Cravo'; e P: laranja-'Pêra'. As setas indicam os marcadores RAPDs. 
TABELA 1- Número de fragmentos RAPDs amplificados e polimórficos entre tangerina- 'Cravo' (C. reticulata Blanco) e laranja-'Pêra' (C. sinensis (L.) Osbeck), para 113 'primers'.

\begin{tabular}{|c|c|c|c|c|c|c|c|c|c|}
\hline \multirow[t]{3}{*}{ 'P rim er' } & \multicolumn{4}{|c|}{ Número de fragmentos } & \multirow[t]{3}{*}{ 'P rim er' } & \multicolumn{4}{|c|}{ Número de fragmentos } \\
\hline & \multirow[t]{2}{*}{ Amplificados } & \multicolumn{3}{|c|}{ Polim órficos } & & \multirow[t]{2}{*}{ A m plificados } & \multicolumn{3}{|c|}{ Polim órficos } \\
\hline & & Forte & Moderado & Total & & & Forte & Moderado & Total \\
\hline OPA 01 & 4 & 0 & 1 & 1 & OPC 19 & 12 & 0 & 1 & 1 \\
\hline $\mathrm{OPAO} 04$ & 7 & 1 & 0 & 1 & O P C 20 & 8 & 2 & 0 & 2 \\
\hline O P A 05 & 9 & 1 & 0 & 1 & OPD 10 & 4 & 1 & 0 & 1 \\
\hline O P A 07 & 10 & 6 & 0 & 6 & OPD 11 & 7 & 2 & 0 & 2 \\
\hline OPA 08 & 11 & 5 & 0 & 5 & OPD 15 & 15 & 1 & 0 & 1 \\
\hline OPA 09 & 8 & 3 & 0 & 3 & OPE 04 & 10 & 1 & 0 & 1 \\
\hline $\mathrm{OPA} 10$ & 6 & 0 & 1 & 1 & OPE 06 & 9 & 2 & 0 & 2 \\
\hline OPA 11 & 7 & 1 & 0 & 1 & OPE 15 & 10 & 1 & 0 & 1 \\
\hline OPA 12 & 6 & 1 & 0 & 1 & OPE 16 & 7 & 3 & 0 & 3 \\
\hline OPA 15 & 5 & 1 & 0 & 1 & OPE 18 & 11 & 1 & 0 & 1 \\
\hline O P A 19 & 9 & 2 & 0 & 2 & OPE 19 & 9 & 1 & 0 & 1 \\
\hline $\mathrm{OPAB} 04$ & 5 & 1 & 1 & 2 & OPE 20 & 7 & 0 & 2 & 2 \\
\hline O P A B 05 & 6 & 1 & 0 & 1 & OP G 08 & 4 & 1 & 0 & 1 \\
\hline O P A B 06 & 9 & 2 & 0 & 2 & OP G 10 & 6 & 1 & 1 & 2 \\
\hline O P A B 07 & 10 & 2 & 0 & 2 & OPG 13 & 11 & 2 & 2 & 4 \\
\hline O P A B 08 & 7 & 0 & 2 & 2 & O P G 17 & 12 & 3 & 2 & 5 \\
\hline O P A B 13 & 7 & 1 & 0 & 1 & OP G 18 & 8 & 2 & 0 & 2 \\
\hline O P A B 14 & 7 & 2 & 0 & 2 & OPG 19 & 10 & 2 & 0 & 2 \\
\hline O P A B 15 & 4 & 1 & 0 & 1 & OPHO 1 & 8 & 2 & 0 & 2 \\
\hline O P A B 17 & 8 & 1 & 0 & 1 & $\mathrm{OPHO} 2$ & 5 & 1 & 0 & 1 \\
\hline O P A B 18 & 5 & 0 & 1 & 1 & $\mathrm{OPH} 15$ & 11 & 1 & 1 & 2 \\
\hline O PATO 4 & 3 & 1 & 0 & 1 & $\mathrm{OPH} 16$ & 6 & 2 & 0 & 2 \\
\hline O PAT 05 & 9 & 1 & 0 & 1 & O P H 19 & 9 & 3 & 0 & 3 \\
\hline O P A T 07 & 13 & 3 & 0 & 3 & O P H 20 & 8 & 1 & 0 & 1 \\
\hline OPAT 13 & 7 & 2 & 0 & 2 & O P M 07 & 16 & 4 & 0 & 4 \\
\hline OPAT 14 & 8 & 2 & 0 & 2 & OPM 11 & 10 & 3 & 0 & 3 \\
\hline OPAT 18 & 9 & 2 & 0 & 2 & OPM 13 & 12 & 0 & 1 & 1 \\
\hline O P A V 02 & 7 & 1 & 0 & 1 & OPNO5 & 6 & 1 & 0 & 1 \\
\hline OPA V 03 & 8 & 0 & 1 & 1 & OPNO 08 & 9 & 2 & 0 & 2 \\
\hline OPA V 05 & 6 & 2 & 0 & 2 & OPNO9 & 8 & 1 & 0 & 1 \\
\hline O P A V 08 & 8 & 1 & 0 & 1 & OPN 14 & 7 & 3 & 1 & 4 \\
\hline OPA V 12 & 8 & 1 & 2 & 3 & OPN 15 & 9 & 4 & 0 & 4 \\
\hline OPA V 16 & 9 & 2 & 0 & 2 & OPN 16 & 7 & 1 & 0 & 1 \\
\hline OPB 02 & 8 & 2 & 0 & 2 & OPP 01 & 9 & 1 & 0 & 1 \\
\hline O Р B 03 & 6 & 2 & 0 & 2 & OPP 05 & 8 & 2 & 0 & 2 \\
\hline O Р В 04 & 6 & 1 & 0 & 1 & OPP 06 & 8 & 2 & 0 & 2 \\
\hline O Р В 05 & 8 & 2 & 0 & 2 & OPP 09 & 9 & 4 & 0 & 4 \\
\hline O P B 08 & 12 & 2 & 0 & 2 & OPP 10 & 6 & 2 & 0 & 2 \\
\hline O Р В 09 & 6 & 2 & 0 & 2 & OPP 11 & 4 & 1 & 0 & 1 \\
\hline O P B 10 & 5 & 1 & 0 & 1 & OPP 12 & 5 & 2 & 0 & 2 \\
\hline O P B 11 & 9 & 1 & 0 & 1 & OPP 18 & 7 & 2 & 0 & 2 \\
\hline O P B 12 & 10 & 1 & 0 & 1 & OPP 20 & 4 & 1 & 0 & 1 \\
\hline O P B 13 & 4 & 1 & 0 & 1 & $O P Q 04$ & 8 & 1 & 0 & 1 \\
\hline O Р B 14 & 6 & 1 & 0 & 1 & OPQ 05 & 11 & 1 & 2 & 3 \\
\hline O P B 17 & 5 & 1 & 0 & 1 & OPQ 06 & 6 & 2 & 1 & 3 \\
\hline O P B 19 & 8 & 2 & 0 & 2 & $O P Q 07$ & 3 & 1 & 0 & 1 \\
\hline O P B 20 & 4 & 1 & 1 & 2 & $O P Q 08$ & 6 & 1 & 0 & 1 \\
\hline OPC 01 & 2 & 1 & 0 & 1 & $O P Q 10$ & 5 & 1 & 0 & 1 \\
\hline $\mathrm{OPC} 03$ & 7 & 3 & 0 & 3 & $O P Q 15$ & 10 & 2 & 1 & 3 \\
\hline OPC 05 & 11 & 2 & 0 & 2 & O P Q 17 & 7 & 0 & 1 & 1 \\
\hline OPC 06 & 6 & 2 & 1 & 3 & OPR 07 & 14 & 1 & 0 & 1 \\
\hline O P C 07 & 4 & 1 & 0 & 1 & OPR 09 & 9 & 1 & 0 & 1 \\
\hline OPCO 9 & 7 & 1 & 0 & 1 & OPR 19 & 10 & 2 & 0 & 2 \\
\hline OPC 10 & 4 & 1 & 0 & 1 & $O P \cup 03$ & 10 & 1 & 0 & 1 \\
\hline OPC 13 & 6 & 1 & 1 & 2 & OPU 05 & 16 & 0 & 1 & 1 \\
\hline $\mathrm{OPC} 14$ & 5 & 1 & 1 & 2 & OPU0 8 & 8 & 1 & 0 & 1 \\
\hline OPC 18 & 1 & 1 & 0 & 1 & Total & 869 & 171 & 30 & 201 \\
\hline
\end{tabular}

por 'primer', ao trabalharem com tangerinas e mexericas. O número de bandas amplificadas normalmente é função da espécie, do 'primer' e das condições da amplificação (Ferreira \& Grattapaglia, 1998).

Para os parentais estudados, foram selecionados 113 'primers' que produziram fragmentos polimórficos, com número de marcadores variando de 1 a 6 por 'primer'. Esses 'primers' amplificaram 869 bandas, sendo 201 (23,13\%) polimórficas, com tamanho variando de 261 a $2961 \mathrm{pb}$ (Figura 1). O número médio de marcadores por 'primer' foi de 1,78. A freqüência de 'primers' polimórficos com $1 ; 2 ; 3 ; 4 ; 5$ e 6 marcadores foi de $49,5 \%, 33,6 \%$, $9,7 \%, 4,4 \%, 1,8 \%$ e $1,0 \%$, respectivamente (Tabela 1 ).

Vários trabalhos visando a selecionar 'primers' e marcadores RAPDs foram feitos com outras espécies de Citrus e gêneros correlacionados. Simone et al. (1998) trabalharam com
C. aurantium e C. latipes, e Cristofani et al. (1999) com C. sunki e Poncirus trifoliata obtendo, respectivamente, 1,42 e 2,18 marcadores RAPDs por 'primer' selecionado. Nesses trabalhos, as diferenças ocorreram, principalmente, em função da composição genética das espécies estudadas.

Em reações RAPDs, normalmente, são amplificados fragmentos entre 500 e $2500 \mathrm{pb}$ (Ferreira \& Grattapaglia, 1998). Neste trabalho, 90,5\% dos marcadores ocorreram nesse intervalo. Cai et al. (1994), Coletta Filho et al. (1998) e Cristofani et al. (1999) obtiveram fragmentos polimórficos de tamanho entre 200 e 3000 $\mathrm{pb}$, ao trabalharem com mais de uma centena de marcadores RAPDs em citros.

Do total de marcadores selecionados, $85,1 \%$ (171) apresentaram intensidade e nitidez acentuadas nos géis de agarose e $14,9 \%$ (30), moderadas; todos sendo recomendados 
TABELA 2- Marcadores RAPDs selecionados em tangerina-'Cravo'(C. reticulata Blanco), laranja-'Pêra' (C. sinensis (L.) Osbeck) e seus híbridos.

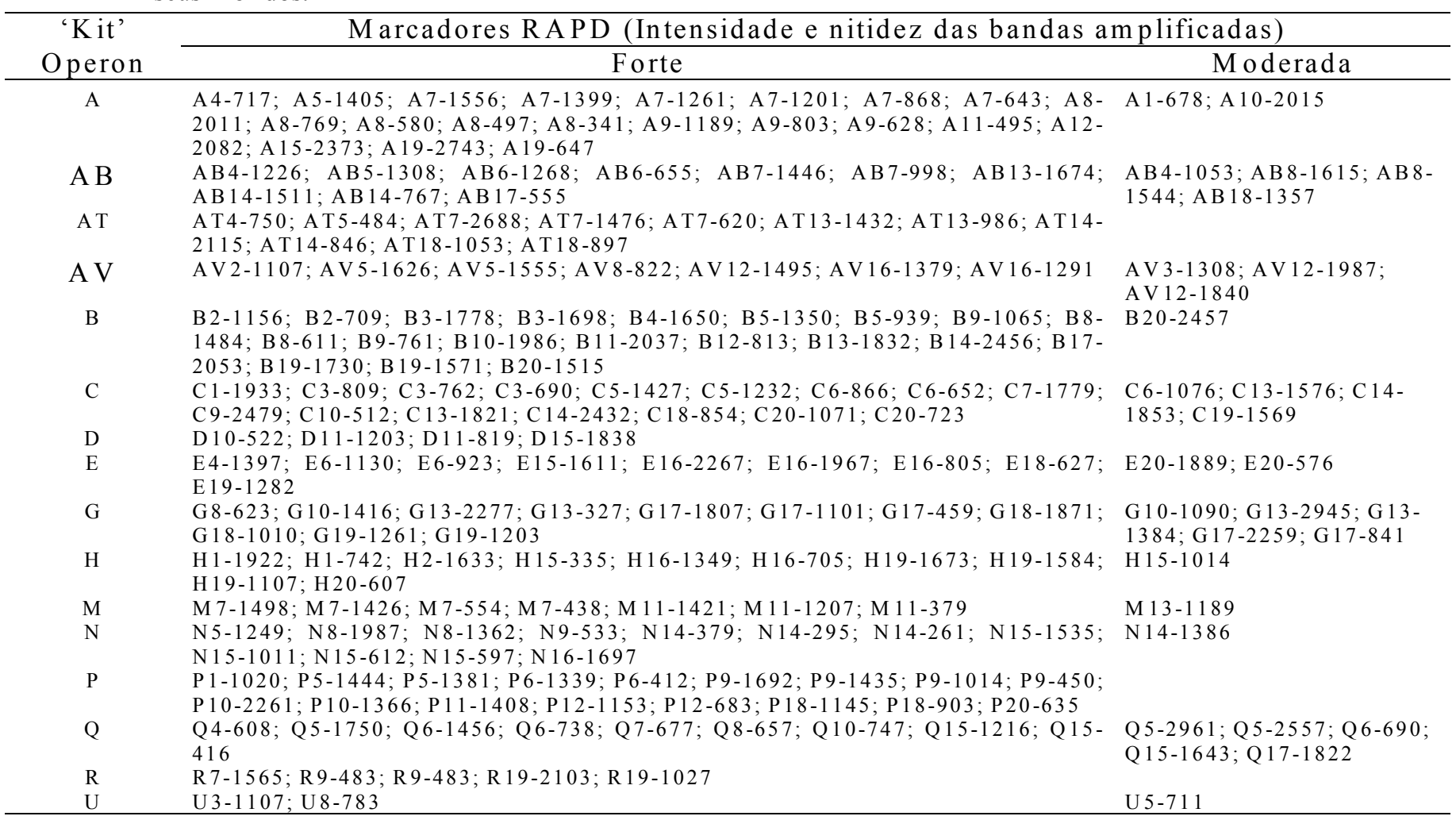

para análises do genoma de tangerina-'Cravo', laranja-'Pêra' e seus híbridos (Tabela 2). As bandas polimórficas de intensidade e nitidez fracas não foram consideradas para evitar interpretações ambíguas. Segundo Ferreira \& Grattapaglia (1998), bandas pouco consistentes ocorrem com todos os tipos de marcadores moleculares, sendo atribuídas, em ensaios RAPDs, ao baixo poder de o 'primer' discriminar sítios de amplificação distintos, à competição entre diferentes sítios de amplificação por substrato e enzima, e à problemas na padronização das condições de amplificação.

Os marcadores RAPDs descritos nas Tabelas 1 e 2 podem ser utilizados para a seleção precoce de híbridos, obtenção de 'fingerprints', estudos de diversidade genética e construção de mapas genéticos. Os 'primers' que apresentaram quatro (OPG13, OPM07, OPN14, OPN15 e OPP09), cinco (OPA08 e OPG17) e seis (OPA07) bandas polimórficas apresentam grande aplicabilidade na seleção precoce de híbridos entre tangerina- 'Cravo' e laranja'Pêra', pois permitem a seleção mais eficiente da maior parte dos híbridos com apenas uma única reação de amplificação, contornando as limitações relacionadas à natureza dominante dos marcadores RAPDs. Uma vez que Simone et al. (1998) e Cristofani et al. (1999) construíram mapas moleculares de espécies de citros, respectivamente, com 157 e 169 marcadores RAPDs e conseguiram localizar genes de interesse agronômico nesses mapas, espera-se que os 201 marcadores selecionados possam ser suficientes para a mesma finalidade.

\section{CONCLUSÕES}

1. A utilização de DNA de boa qualidade, extraído por método CTAB, e a padronização das condições da PCR possibilitam a obtenção de reações de RAPD com elevada reprodutibilidade, mesmo em diferentes termocicladores.

2. Marcadores RAPDs consistentes foram obtidos entre os parentais tangerina- 'Cravo' e laranja-'Pêra' utilizando diferentes 'primers', que estão sendo utilizados para a seleção precoce de híbridos zigóticos, estudos de diversidade genética e construção de mapas genéticos de ligação.

3. Os 'primers' que amplificam um maior número de marcadores RAPDs são os menos freqüentes; existem 'primers' que amplificam até seis bandas polimórficas entre os parentais tangerina-'Cravo' e laranja-'Pêra'.

4. Nas reações de amplificação do DNA de tangerina- 'Cravo' e laranja-'Pêra', a proporção de bandas polimórficas em relação às monomórficas é de, aproximadamente, 1:4 para os 'primers' selecionados.

\section{REFERÊNCIAS BIBLIOGRÁFICAS}

CAI, Q.; GUY, C.L.; MOORE, G.A. Extension of the linkage map in Citrus using random amplified polymorphic DNA (RAPD) markers and RFLP mapping of cold-acclimation-responsive loci. Theoretical and Applied Genetics, Berlin, v.89, p.606-614, 1994.

COLETTA FILHO, H.D.; MACHADO, M.A.; TARGON, M.L.P.N.; MOREIRA, M.C.P.; POMPEU JR., J. Analysis of the genetic diversity among mandarins (Citrus spp.) using RAPD makers. Euphytica, Wageningen, v.102, p.133-139, 1998.

CRISTOFANI, M.; MACHADO, M.A.; GRATTAPAGLIA, D. Genetic linkage maps of Citrus sunki Hort. ex. Tan. and Poncirus trifoliata (L.) Raf. and mapping of citrus tristeza virus resistence 
gene. Euphytica, Wageningen, v.109, p.25-32, 1999.

CRUZ, R.P.; MILACH, S.C.K. Análise de RAPD. In: MILACH, S.C.K. (Ed.), Marcadores moleculares em plantas. Porto Alegre, 1998. p.107-116.

DENG,Z.N.; GENTILE, A.; NICOLOSI,E.; DOMINA,F.; VARDI, A.; TRIBULATO, E. Identification of in vivo and in vitro lemon mutants by RAPD markers. Journal of Horticultural Sciences, Ashford, v.70, p.117-125, 1995.

FEDERICI, C.T.; FANG, D.Q.; SCORA, R.W.; ROOSE, M.L. Phylogenetic relationships within the genus Citrus (Rutaceae) and related genera as revealed by RFLP and RAPD analysis. Theoretical and Applied Genetics, Berlin, v.96, p.812-822, 1988.

FERREIRA, M.E.; GRATTAPAGLIA, D. Introdução ao uso de marcadores moleculares em análise genética. 3 . ed. Brasília:EMBRAPA-CENARGEN, 1998.220p.

GMITTER, F.G.; XIAO, S.Y.; HUANG, S.; HU, X.L.; GARNSEY, S.M.; DENG, Z. A localized linkage map of the virus tristeza virus resistance gene region. Theoretical and Applied Genetics, Berlin, v.92, p.688-695, 1996.

KEIL, M.; GRIFFIN, A.R. Use of random amplified polymorphic DNA (RAPD) markers in the discrimination and verification of genotypes in Eucalyptus. Theoretical and Applied Genetics, Berlin, v.89, p.442-450, 1994.

MACHADO, M.A.; COLETTA FILHO, H.D.; TARGON, M.L.P.N.; POMPEU Jr., J. Genetic relationship of Mediterranian mandarins (Citrus deliciosa Tenore) using RAPD markers. Euphytica, Wageningen, v.92, p.321-326, 1996.

MACHADO, M.A.; SILVERIO, J.L.; BAPTISTA, C.R.; LARANJEIRA, F.F.; BERETTA, M.J.G. Avaliação de transmissão e seleção de variedades à clorose variegada dos citros. Laranja, Cordeirópolis, v.14, n.1, p.167-176, 1993.

MURRAY, M.G.; THOMPSON, W.F. Rapid isolation of high molecular weight plant DNA. Nucleic Acid Research, Oxford, v.8, p.4321-4325, 1980.

OLIVEIRA, R.P.; NOVELLI, V.M.; MACHADO, M.A. Freqüência de híbridos em cruzamento entre tangerina- 'Cravo' e laranja'Pêra': análise de marcadores morfológicos e RAPD. Pesquisa Agropecuária Brasileira, Brasília, v.35, n.9, p.1895-1903, 2000.

SAMBROOK, J.; FRISTSH, E.F.; MANIATS, T. Molecular cloning; a laboratory manual. New York: Cold Spring Harbor, 1989.

SIMONE, M.D.; RUSSO, M.P.; PULEO, G.; MARSAN, P.A.; LORENZONI, C.; MAROCCO, A.; RECUPERO, G.R. Construction of genetic maps for Citrus aurantium and C. latipes based on AFLP, RAPD and RFLP markers. Fruits, Paris, v.53, p.383-390, 1998.

WILLIAMS, J.G.K.; KUBELIK, A.R.; LIVAK, K.J.; RAFALSKI, J.A.; TINGEY, S.V.; DNA polymorphisms amplified by arbitrary primers are useful as genetic markers. Nucleic Acids Research, Oxford, v.18, p.6531-6535, 1990. 